\title{
Mechanical and Durability Properties of Fly Ash Based Concrete Exposed to Marine Environment
}

\author{
Sarfaraz Ahmed Kagadgar, Suman Saha, C. Rajasekaran \\ Department of Civil Engineering, National Institute of Technology Karnataka Surathkal, India \\ e-mail:ksarfaraz7@yahoo.co.in, sumansaha.civil@gmail.com, bcrajasekaran@ nitk.ac.in
}

\begin{abstract}
Efforts over the past few years for improving the performance of concrete suggest that cement replacement with mineral admixtures can enhance the strength and durability of concrete. Feasibility of producing good quality concrete by using alccofine and fly ash replacements is investigated and also the potential benefits from their incorporation were looked into. In this study, an attempt has been made to assess the performance of concrete in severe marine conditions exposed upto a period of 150 days. This work investigates the influence of alccofine and fly ash as partial replacement of cement in various percentages (Alccofine - 5\% replacement to cement content) and (fly ash $-0 \%, 15 \%, 30 \%, 50 \% \& 60 \%$ to total cementitious content) on mechanical and durability properties (Permit ion permeability test and corrosion current density) of concrete. Usage of alccofine and high quantity of fly ash as additional cementitious materials in concrete has resulted in higher workability of concrete. Inclusion of alccofine shows an early strength gaining property whereas fly ash results in gaining strength at later stage. Concrete mixes containing 5\% alccofine with $15 \%$ fly ash replacement reported greater compressive strength than the other concrete mixes cured in both curing conditions. Durability test conducted at 56 and 150 days indicated that concrete containing higher percentages of fly ash resulted in lower permeability as well lesser corrosion density.
\end{abstract}

Key words: Concrete, Marine, Alccofine, Fly ash, Durability, Corrosion, Permeability.

\section{Introduction}

Concrete is the most widely used man made material in the world because of its versatility and relative low cost. Concrete was considered to be very long-lasting material, which requires almost no maintenance. This assumption is largely true, except when it is exposed to highly aggressive environment conditions. Concrete structures are built in highly polluted urban and industrial areas, aggressive marine environments, harmful sub-soil water in coastal area and many other hostile conditions, where other construction materials are found not to be sustained for a long time. Since the usage of concrete in recent times, has become very high to structures in highly aggressive conditions, the earlier impression that concrete is a very 
durable material is being at risk, particularly on the failures of structures at early ages in the recent past.

Concentrating on compressive strength of concrete alone is one of the main reasons for deterioration of concrete in the past. As a result, strength enhancement of concrete gained more importance to the advancement in concrete technology. It is now well established that strength of concrete, which is exposed over its entire life, alone is not sufficient to resist the effect of harsh environmental condition. Therefore, both strength and durability have to be considered explicitly at the design stage. It is interesting to consider yet another view point regarding strength and durability relationship. Chloride attack to the concrete structure is one of the important aspects for the durability of concrete, especially in chloride rich environment including coastal climates. The present day admixtures generally contain negligible quantity of chloride. Again chlorides can enter the concrete by diffusion from environment.

Penetration of chlorides from sea water is the main cause of de-passivation of steel reinforcement and subsequent damage to marine concrete structures. The usual precautions are a low w/c ratio and high concrete cover to steel. These have however practical limitations. Carbonation induced corrosion also is usually prevented by a low w/c and sufficient cover to steel. A high chloride penetration resistance may be obtained by adding hydraulic or pozzalanic minerals such as GGBS, silica fume and fly ash to the cement matrix. The effect of the addition is that, the pore structure becomes finer and possibly, the chloride binding capacity also becomes higher.

Less chloride intensities was observed in concretes containing fly ash and slag compared to OPC concretes. To determine chloride resistivity of concrete, corrosion of reinforcement in concrete was identified in the development of accelerated techniques. They concluded that short term and accelerated methods for determining durability of concrete may mislead if these procedures are not considering long term material properties related to performance for a long time [1]. The chloride binding capacity of cement paste was found to be increased with the increase of fly ash content in concrete upto $50 \%$ and then started to decline. With the increment of chloride exposure concentration and $\mathrm{w} / \mathrm{b}$ ratio, chloride binding capacity increased [2]. This experimental investigation concluded that notched mortar beam specimens produced with $15 \%$ fly ash and with water/binder ratio of 0.3 obtained highest bond strength of mortar-aggregate interface and fracture toughness. With high quantity of fly ash, interfacial bond strength and fracture toughness of concrete at 28 days were reduced, but after 90 days this reductions were recovered by the concrete [3]. Inclusion of $30 \%$ fly ash in concrete causes increase in porosity compared to conventional concrete during early days (up to 14 days) of hydration. The advantage of addition of fly ash is reflected after 28 days of hydration and beyond this age conventional concrete did not show any significant reduction up to an age of 365 days. The fly ash admixed concrete exhibits a reducing trend on the porosity even after 28 days [4]. Improvement of the sulfate resistance of mortars containing sufficient fly ashes ( $25 \%$ fly ash $+75 \%$ cement) was found in this study and they concluded that silica fume was preferable to use for high sulfate resistance while fly ash having high calcium content was used to produce mortar [5]. The findings of chloride diffusion on concrete exposed to below ground condition in a coastal area was reported considering the parameters w/b ratio, curing period, cement content, degree of consolidation given to concrete and use of admixtures in this study. Chloride diffusion was found to be decreased with curing period and with decrease in $\mathrm{w} / \mathrm{b}$ ratio. Chloride concentration in concrete also decreased with degree of consolidation 
[6]. Chloride ingress of concretes containing silica fume, metakaolin and zeolite under various in-situ exposure conditions were studied and compared these concretes with plain concrete with various $\mathrm{w} / \mathrm{b}$ ratio. The chloride diffusion coefficient was higher in tidal zone than in splash zone for specimens with different $w / b$ ratios. The sequence of exposure conditions in terms of chloride amounts observed in the specimens from most to least at a depth of $20 \mathrm{~mm}$ was as follows: splash > tidal > soil > atmosphere zones. Natural zeolite exhibited good performance in terms of improving the durability of concrete in harsh environments [7]. Chloride penetration in concrete was found maximum in the tidal zone followed by the spray zone and the atmospheric zone. The diffusion coefficients vary significantly with concrete quality and exposure condition, as they influence the pore structure and water cement in the pores [8].

\section{Objectives and Scope}

Concrete mixes made with blended cements may significantly increase the resistance against chloride ingress and consequently increase the time to initiation of corrosion. Therefore, in this experimental work, an attempt has been made to study the performance of concrete exposed at marine conditions for different durations incorporating fly ash from low volume to high volume and 5\% (by the mass of OPC) alccofine. The main objectives of this study are to determine performance of concrete in terms of strength (compressive strength, splitting tensile strength and flexural strength) and durability (ion permeability and corrosion of steel) for different fly-ash proportion replacements and inclusion of alccofine in concrete. A comparative analysis of the performance of concrete cured at normal and marine condition for different duration is also done.

\section{Materials and Methodology}

\subsection{Materials}

\subsubsection{Ordinary Portland Cement (OPC)}

Ordinary Portland cement of 43 Grade (RAMCO Cement), which conforms the guidelines given by IS 8112-1989 [9], was used. In order to determine the properties, tests were carried out as per IS 4031 [10]. The results of the tests are shown in the Table 1.

Table 1: Physical properties of Ordinary Portland Cement

\begin{tabular}{|c|c|}
\hline Properties & Results Obtained \\
\hline Specific Gravity & 3.10 \\
\hline Fineness $\left(\mathrm{m}^{2} / \mathrm{kg}\right)$ & 300 \\
\hline Standard Consistency & $30 \%$ \\
\hline Initial setting time (minutes) & 90 \\
\hline Final setting time (minutes) & 210 \\
\hline Soundness (By Le chatelier mould) $(\mathrm{mm})$ & 2 \\
\hline
\end{tabular}




\subsubsection{Fly ash}

Fly ash was collected from Udupi Power Corporation, Udupi. The specific gravity of fly ash was found out to be 2.16. Amount of fly Ash retained in $45 \mu \mathrm{m}$ sieve was measured equal to $30 \%$, which is within the prescribed limit. It was reported that, it is a Class-F fly ash with low calcium content.

\subsubsection{Alccofine}

Alccofine is a new generation, which consists of particle size much finer than other cementitious materials like cement, fly ash, silica fume etc. [11]. Alccofine 1203 is a microfine mineral additive, which is a specially processed product based on slag of high glass content with high reactivity obtained through the process of controlled granulation. It is ultra fine slag has a larger total surface area for hydration and pozzolanic reaction, compared to normal GGBS. Alccoffine 1203 is a finest cementitious material, which can replace silica fume in high performance concrete. Properties of alccofine are tabulated in Table 2.

Table 2: Properties of alccofine

\begin{tabular}{|c|c|}
\hline Properties & Values obtained \\
\hline Specific gravity & 2.90 \\
\hline Fineness $\left(\mathrm{cm}^{2} / \mathrm{g}\right)$ & 12000 \\
\hline Bulk density $\left(\mathrm{kg} / \mathrm{m}^{3}\right)$ & 800 \\
\hline
\end{tabular}

\subsubsection{Fine Aggregates}

Locally available river sand passing through $4.75 \mathrm{~mm}$ sieve was used in this study. Sand was free from organic matter and silt. Properties of sand such as fineness modulus, specific gravity etc. were determined as per IS 2386-1963 (Part I) [12]. Table 3 gives the properties of fine aggregates used in this investigation and Fig. 1 shows the particle size distribution of sand.

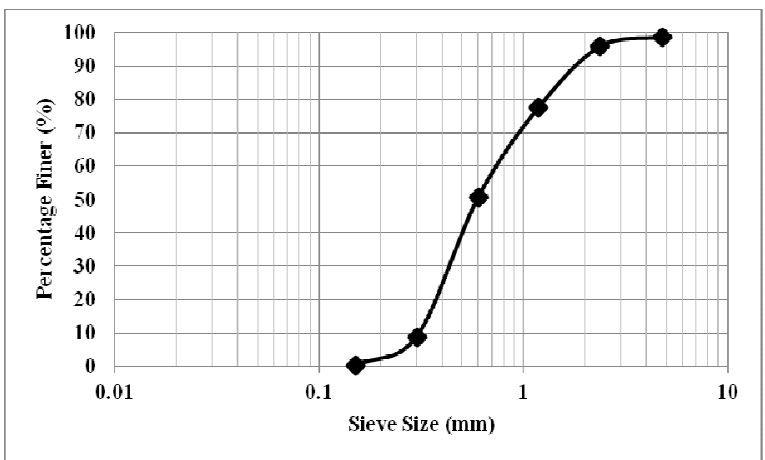

Figure 1: Particle Size Distribution of Sand

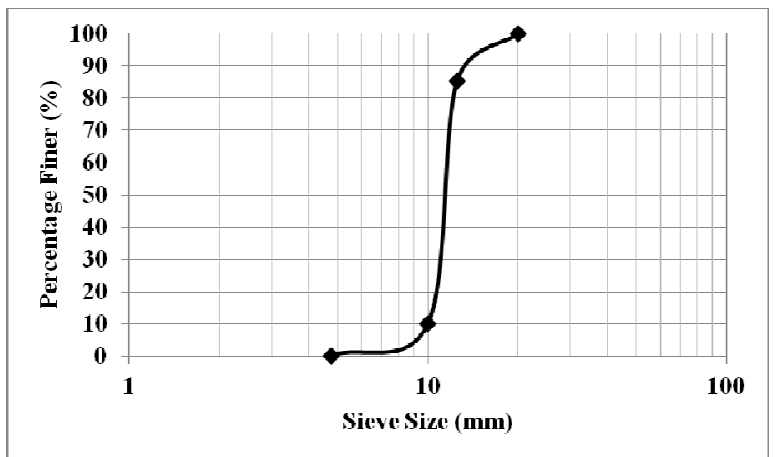

Figure 2: Particle Size Distribution of Coarse Aggregates

\subsubsection{Coarse Aggregates}

Locally available crushed stone coarse aggregate of $20 \mathrm{~mm}$ down size were used. The aggregates were a mixture of rounded and coarse aggregates. The various properties of aggregates are determined as per IS 2386 (Part III, IV): 1963 (Reaffirmed 1997) [12] and the 
specifications are checked as per IS 383: 1970 (Reaffirmed 1997) requirements [13]. Table 3 gives the properties of coarse aggregates used in this investigation and figure 2 shows the particle size distribution of coarse aggregates.

Table 3: Properties of aggregates

\begin{tabular}{|c|c|c|c|}
\hline \multicolumn{2}{|c|}{ Properties } & Fine Aggregates & Coarse Aggregates \\
\hline \multicolumn{2}{|c|}{ Specific Gravity } & 2.60 & 2.65 \\
\hline $\begin{array}{c}\text { Bulk Density } \\
\left(\mathrm{kg} / \mathrm{m}^{3}\right)\end{array}$ & Loose & 1450 & 1460 \\
\cline { 2 - 4 }$\%$ of Voids & 1650 & 1640 \\
\hline \multicolumn{2}{|c|}{$\%$ ompacted } & $38 \%$ & $40 \%$ \\
\hline
\end{tabular}

\subsubsection{Water}

The amount of water used in the mix design has a direct effect on the properties of concrete. The quantity of water used was as per mix design. In this work, normal tap water was used for mixing and the $\mathrm{pH}$ value of used water was 8.2.

\subsubsection{Concrete mixes}

Designing a proper mix for a particular strength and workability is very important for assessing the properties of the materials used in concrete. Each material will influence the properties of concrete in its own way. Concrete mix was designed following the several guidelines of Indian Standard IS 456:2000[14] and IS 10262:2009[15]. Water/binder ratio (w/b) was considered as 0.45 throughout the work. Alccofine was added to each mixes by $5 \%$ of total OPC quantity excluding control mix. Materials required for one cubic meter concrete of the various mixes tested herein for evaluation of their properties are shown in Table 4.

Table 4: Materials required per cubic meter concrete

\begin{tabular}{|c|c|c|c|c|c|c|c|}
\hline Mix & $\begin{array}{c}\text { Total amount of } \\
\text { cementitious } \\
\text { material }(\mathrm{kg})\end{array}$ & $\begin{array}{c}\text { Cement } \\
(\mathrm{kg})\end{array}$ & $\begin{array}{c}\text { Alccofine } \\
(\mathrm{kg})\end{array}$ & $\begin{array}{c}\text { Fly } \\
\text { ash } \\
(\mathrm{kg})\end{array}$ & $\begin{array}{c}\text { Fine } \\
\text { Aggregate } \\
(\mathrm{kg})\end{array}$ & $\begin{array}{c}\text { Coarse } \\
\text { Aggregate } \\
(\mathrm{kg})\end{array}$ & $\begin{array}{c}\text { Water } \\
(\mathrm{kg})\end{array}$ \\
\hline CM & 455 & 455 & -- & -- & 693 & 1179 & \\
\cline { 1 - 7 } F-15 & 455 & 368 & 19 & 68 & 670 & 1140 & \multirow{2}{*}{186} \\
\cline { 1 - 6 } F-30 & 455 & 303 & 16 & 136 & 660 & 1124 & \\
\hline F-50 & 455 & 216 & 11 & 228 & 648 & 1103 & \\
\hline
\end{tabular}

CM: Control Mixes; F-15: concrete mixes with 15\% fly ash; F-30: concrete mixes with $30 \%$ fly ash; F-50: concrete mixes with 50\% fly ash; F-60: concrete mixes with $60 \%$ fly ash.

\subsection{Methodology}

For this experimental work, specimens were cast with Ordinary Portland Cement (OPC), alccofine (5\% replacement of cement content) and varied percentage of fly ash varying from low volume to high volume fly ash. OPC is replaced by fly ash from $0 \%, 15 \%, 30 \%, 50 \%$ and $60 \%$ in the different mixes. Cylindrical specimens, cube specimens and beam specimens were tested for splitting tensile strength, compressive strength and flexural strength respectively. 
Reinforced cubes for corrosion density and slabs to conduct permeability test. Testing periods were scheduled as 7, 28, 56, 90, 120 and 150 days.

\subsubsection{Preparation, casting \& curing of samples}

Designed quantities of sand, OPC, fly ash, and coarse aggregates were added to the mixer in that order and after one minute of dry mixing, water was added to the mixer. The workability of the resulting mix was determined using a slump test. Concrete is then filled into the standard moulds and fully compacted using a table vibrator. For each type of concrete mixes, cubes $(150 \mathrm{~mm} \times 150 \mathrm{~mm} \times 150 \mathrm{~mm})$, cylinders $(150 \mathrm{~mm}$ in diameter and $300 \mathrm{~mm}$ in height $)$ and beams $(100 \mathrm{~mm} \times 100 \mathrm{~mm} \times 500 \mathrm{~mm})$ were cast to study compressive strength, splitting tensile strength and flexural strength of concrete respectively. To study the durability of the concrete, concrete cubes with one central $16 \mathrm{~mm}$ diameter rebar and concrete slabs were cast to determine reinforcement corrosion density and permeability respectively. Demoulding of specimens was done after 24 hours of casting. After careful demoulding, all specimens are subjected to two different types of curing conditions. One set of concrete samples was cured in normal curing condition and the other set of concrete samples were cured in marine condition until the day of testing. Marine exposure conditions were maintained in laboratory only by changing the seawater regularly so that all the properties of sea water remain same.

\subsubsection{Tests on concrete}

In fresh state, workability of concrete in terms of slump was measured using the slump cone test. Fresh concrete mix was also checked for signs of segregation and bleeding during trial mixes. In hardened state the mechanical properties (compressive strength, splitting tensile strength and flexural strength) and durability properties (permit ion permeability test and corrosion rate measurements test) of concrete were evaluated.

Compression testing of cube specimens was carried out in a compression testing machine of capacity $2000 \mathrm{kN}$, as per the guidelines given by IS 516-1959 [16]. Concrete cubes are tested for their compressive strength at 7, 28, 56, 90, 120 and 150 days of casting. Flexural strength tests were carried out on prisms as per the guidelines by IS 516-1959 [16] and IS: 9399-1979 [17] at the age of 28 days. The tests were conducted on a $100 \mathrm{kN}$ capacity, analog type flexural testing machine. Splitting tensile strength test is carried out as per IS: 5816-1999[18].

\subsubsection{Durability Tests}

Durability of concrete may be defined as the ability of concrete to resist weathering action, chemical attack, and abrasion while maintaining its desired engineering properties. Durability is a measure of permeability of concrete rather than its strength.

\subsubsection{Permit ion permeability test}

Permit ion permeability test can be used to measure the ionic transport resistance offered by concrete and other such porous materials, both in laboratory and on site. It is a unique instrument for determining the coefficient of ionic transport in situ and hence, there is no need to extract cores from structures for laboratory testing. Using this equipment, a steady state ionic flow is established. The rate of conductivity is calculated and can be used as a measure of durability of concrete. 
Absolute average temperature during steady state condition, for which the steady rate of chlorides was obtained $(\mathrm{K})$. To determine the concentration gradient, the chloride concentration obtained should be plotted against time. The slope of the concentration vs. time graph during steady state is termed as dc/dt. Identification of the test voltage applied and calculation of the $\mathrm{D}_{\text {mig in situ }}$ are done using the equation (1)

$$
D_{\text {mig in situ }}=-\left(\frac{d e T}{d t E}\right)\left(\frac{R}{g C F}\right)\left(\frac{L}{A} V\right)
$$

Where, Potential Difference E, in volt $=60 \mathrm{~V}$ DC,

Concentration of the ion source solution $(\mathrm{NaCl}) \mathrm{C}$, in $\mathrm{ppm}=0.55 \mathrm{M}$, i.e. $0.55 \times 10^{3}$

Volume of the outer cell, $\mathrm{V}$, in $\mathrm{m}^{3}=6.5 \times 10^{-4}$

Average flow length, $\mathrm{L} / \mathrm{A}$, in $\mathrm{m}^{-1}=3.74 \mathrm{~m}^{-1}$

Valency of chloride ions, $\mathrm{z}=-1$

Faraday's constant, $\mathrm{F}$, in $\mathrm{c} / \mathrm{mol}=96500 \mathrm{c} / \mathrm{mol}$

Universal gas constant, R, in J/K.mol = 8.31 J/K.mol

Average temperature during steady state, $\mathrm{T}$, in kelvin $=\left(273+\mathrm{t}^{\circ} \mathrm{C}\right)$

\subsubsection{Corrosion rate measurements}

Based on Linear Polarization Resistance (LPR) method, the corrosion rates for individual specimens were measured with Applied Corrosion Monitoring (ACM) instrument. In LPR method, reinforcing steel bar was polarized potentiostatically by an inner auxiliary electrode and the real time plot of current response was displayed on a laptop screen which controls the guard ring device. Area of steel polarized was confined by a current applied from an outer guard ring electrode. Area of steel was controlled by two sensor electrodes positioned between the inner auxiliary and outer guard ring electrode. Typical corrosion rates from LPR are presented in Table 5. Linear Polarization Resistance $\left(R_{P}\right)$ was determined from the slope of the plot of applied potential versus the measured current. Corrosion current density was then calculated using the Stern-Geary formula.

$$
i_{\text {oorr }}=\frac{B}{R p}
$$

Where, $\mathrm{i}_{\text {corr }}=$ Corrosion current density, $\mathrm{R}_{\mathrm{p}}=$ Polarisation resistance $\left(\mathrm{k} \Omega \mathrm{cm}^{2}\right), \mathrm{B}=26 \mathrm{mV}$ for steel in active condition (Fontana, 2005).

Table 5: Typical corrosion rates from LPR measurements

\begin{tabular}{|c|c|}
\hline Corrosion classification & Corrosion current density $\mathbf{i}_{\text {corr }}\left(\boldsymbol{\mu} \mathbf{A} / \mathbf{c m}^{2}\right)$ \\
\hline Passive/very low & Upto 0.2 \\
\hline Low/moderate & 0.2 to 0.5 \\
\hline Moderate/high & 0.5 to 1 \\
\hline High & $\square 1.0$ \\
\hline
\end{tabular}

\section{Results and Discussion}

\subsection{Workability}

Workability of concrete in terms of slump was measured using the slump cone test. Higher slump values of concrete mixes were observed with the increasing quantity of fly ash. Higher quantity helps to get high workable concrete. Fig. 3 shows the variation of workability for the different mixes. 


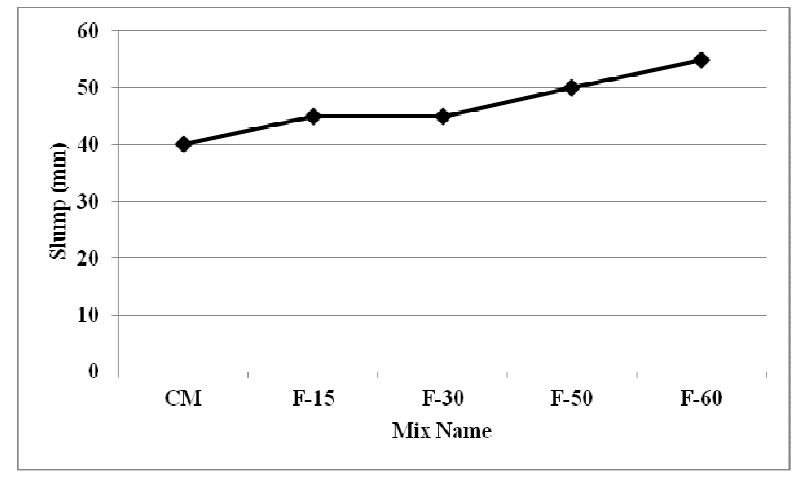

Figure 3: Variation of Slump Value of Different Mixes

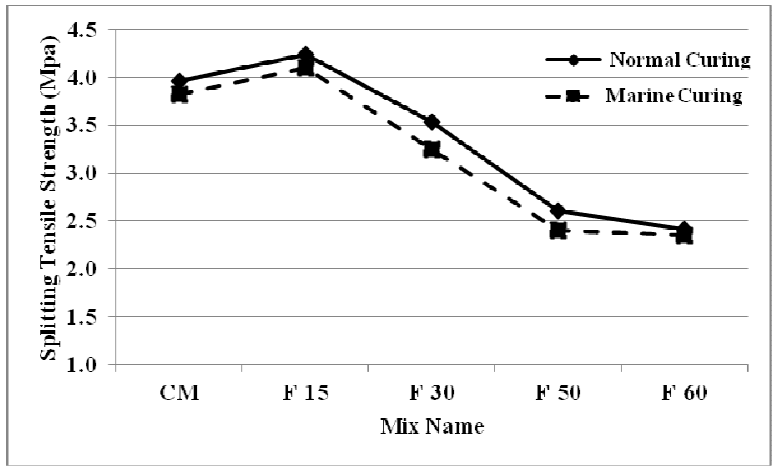

Figure 4: Variation of Splitting Tensile

Strength of different mixes

\subsection{Compressive Strength}

Compressive strength of concrete cubes, $150 \mathrm{~mm}$ size at different ages for the various curing conditions stated earlier were determined and strength development with age is plotted. The effect of curing is studied for a period of 150 days. It is seen that, while early strength of fly ash mixed concrete are lower than those of control mix at 7 days, subsequently they have attained higher strengths at later ages. It was observed that the variation in compressive strength almost tends to be small with increase in age. It was observed that concrete mix having $15 \%$ fly ash replacement with 5\% alccofine showed highest compressive strengths for all the curing conditions. Fig. 5 shows the variation of compressive strength of fly ash based concrete for both type of curing conditions at different ages.

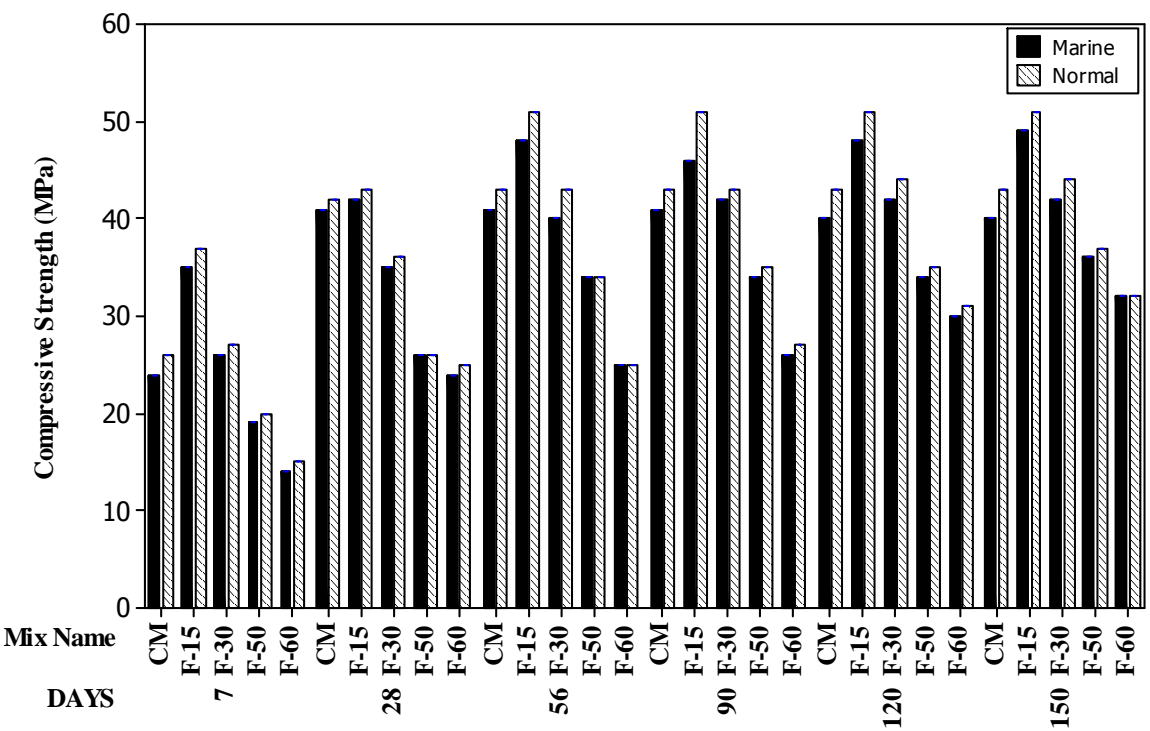

Figure 5: Variation of compressive strength of concrete mixes for different percentage of fly ash at different ages. 


\subsection{Splitting Tensile Strength}

In order to determine splitting tensile strength of fly ash based concrete, cylindrical specimens were tested after 28 days of curing. Splitting tensile strengths showed similar behavior to that of compressive strengths of different mixes showing higher strength with $15 \%$ replacement of fly ash. Samples cured at marine environment shows less strength than the samples cured at normal tap water. The profile of splitting tensile strength under both curing conditions has been shown in Fig. 4.

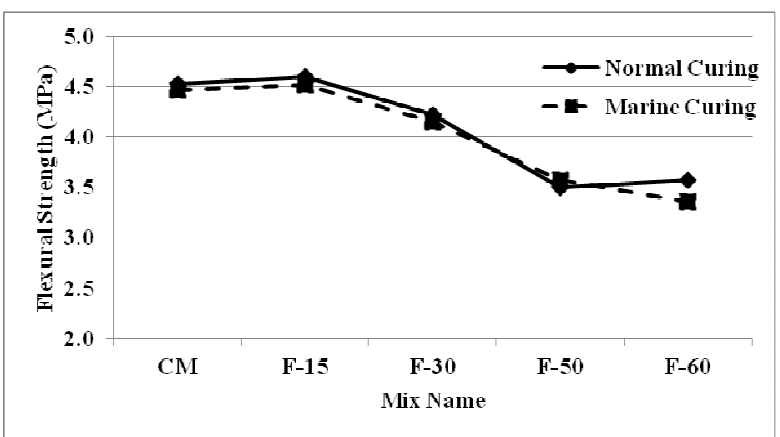

Figure 6: Variation of Flexural Strength of different mixes

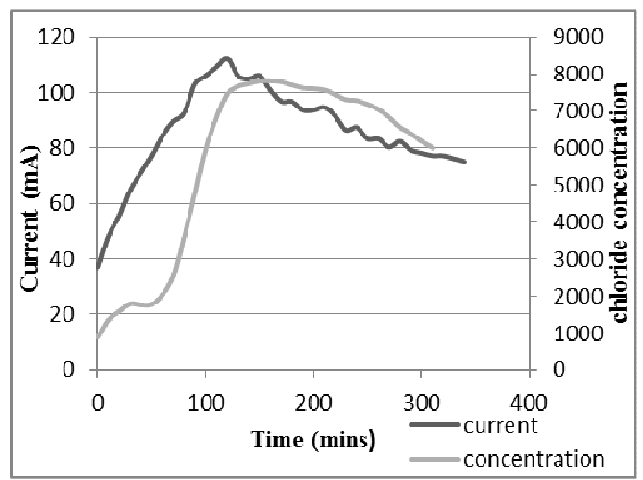

Figure 7: Variation of current Vs chloride concentration for F-15 at 56 days

\subsection{Flexural Strength}

Fig. 6 show the variation of flexural strength of fly ash based concrete cured for 28 days at normal and marine conditions. Flexural strengths showed similar behavior to that of compressive strengths showing higher strength with $15 \%$ replacement of fly ash.

\subsection{Durability Tests}

The permit ion permeability test is conducted to determine the durability of the concrete for various mixes. Fig. 7 shows variation of current vs chloride concentration for F-15 mixes at 56 days of marine curing and follows the calculation to determine $\mathrm{D}_{\mathrm{mig}}$ in situ.

\subsubsection{Permit ion permeability test}

The permit ion permeability test is conducted to determine the durability of the concrete for various mixes. Fig. 7 shows variation of current vs chloride concentration for F-15 mixes at 56 days of marine curing and follows the calculation to determine $\mathrm{D}_{\text {mig in situ. }}$

From the graph we obtain dc/dt and the calculation part is as follows

$$
\begin{gathered}
\mathrm{T}=273+34.5=307.48 \mathrm{~K} \\
\mathrm{dc} / \mathrm{dt}=1.826 \times 10^{-3} \mathrm{mmol} / \mathrm{l} . \mathrm{s} \\
\text { Dmig in situ }=-\left(\frac{d c T}{d t E}\right)\left(\frac{\mathrm{K}}{\Xi C F}\right)\left(\frac{L}{A} \mathrm{~V}\right) \\
\mathrm{D}_{\text {mig in situ }}=-\left(1.826 * 10^{-3} \times \frac{307.48}{60}\right) *\left(\frac{3.31}{(-1) \times 0.55 \times 10^{3} \times 96500}\right) *\left(6.5 * 10^{-4} \times 3.74\right)
\end{gathered}
$$


$\mathrm{D}_{\text {mig in situ }}=3.562 \times 10^{-12} \mathrm{~m}^{2} / \mathrm{s}$

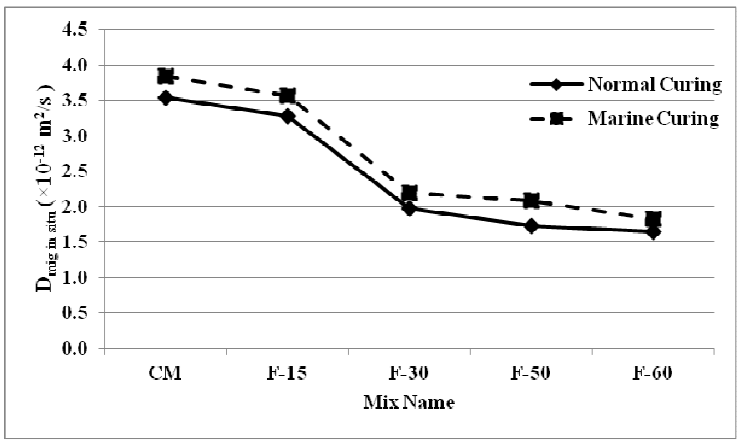

Figure 8: $\mathrm{D}_{\text {mig in situ }}$ for different mixes at 56 days.

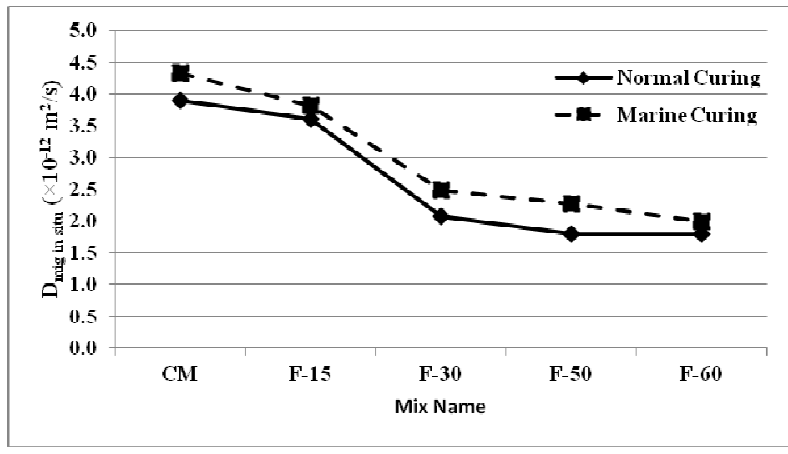

Figure 9: $\mathrm{D}_{\text {mig in situ }}$ for different mixes at 150 days

Lower the rate of migration coefficient, lower will be the permeability of concrete, which means that the concrete will be denser with lesser voids and better durability. It is evident that the rate of conductivity and migration coefficient decreases with the increase in the fly ash content in concrete for both marine and normal curing conditions. Decrease in rate of migration coefficient with the increase in the fly ash content is an indication of denser concrete with better compact packing of concrete ingredients with lesser voids. It can be concluded that, with the increase in fly ash content, the permeability of concrete decreases leading to concrete which is more durable. Fig. 8 and Fig. 9 show the variation of $D_{\text {mig in situ }}$ of different concrete mixes cured at normal and marine condtions at 56 days and 150 days respectively.

\subsubsection{Measurement of corrosion current density}

Corrosion rate is measured in terms of corrosion current density, $i_{c o r r}$, and is a quantitative index, which represents an overall estimate of the corrosion attack on reinforcement. To study the induced corrosion levels of specimens, corrosion current density was measured using the corrosion measuring system "Gill AC" (Applied Corrosion Monitoring System). Corrosion rate was measured after 150 days of curing in marine water. The corrosion current densities for each mixes are shown in Fig. 10.

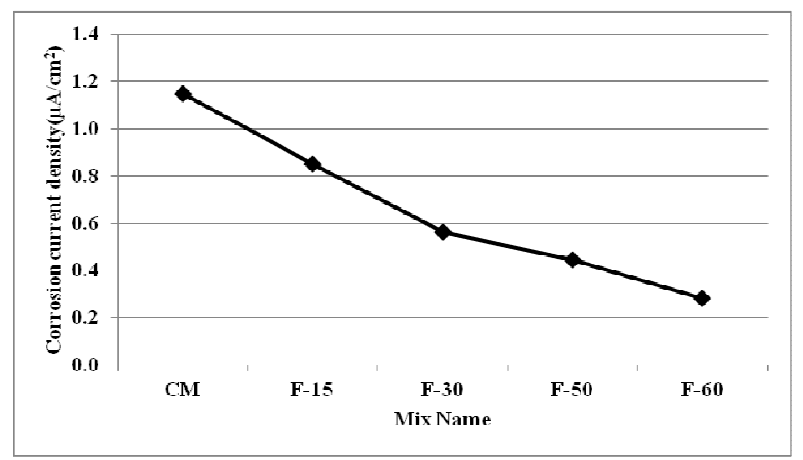

Figure 10: Corrosion current density of different mixes at 150 days 
It was observed that the degree of corrosion reduces with the increase in the quantity of fly ash in the concrete mix. It can be observed that with increase in fly ash content the mix was denser and hence it reduced the permeability and hence the corrosion level reduced with the increase in fly ash contents in the mix.

\section{Conclusions}

This project is aimed to study the behavior of concrete exposed to marine environment for different proportions of fly ash varying from low volume to high volume fly ash. It has been attempted to understand the possible effects of admixture (alccofine) for various proportions of fly ash. Hence at this stage based on the results, following conclusions are drawn.

$>$ The slump value was increased with the increase in percentage of fly ash with alccofine admixture. Concrete with $60 \%$ fly ash and $5 \%$ alccofine yielded $15 \mathrm{~mm}$ more slump than control mix. This shows that concrete with alccofine and fly ash replacement produce better workable concrete with same water content.

$>$ The present study showed that the concrete incorporating fly ash and alccofine withstood higher compressive loads than reference concrete, with 5\% alccofine and $15 \%$ fly ash mix showing highest increase in compressive strength of $42.30 \%$ than that of reference mix at the age of 7 days in normal curing.

$>$ Fly ash at $15 \%$ replacement with $5 \%$ alccofine yielded highest compressive strength of $45.83 \%$ than that of control mix at the age of 7 days in marine curing. Thus this is the best mix satisfying compressive strength of concrete in normal curing and marine curing.

$>$ The concrete containing $15 \%$ fly ash and 5\% of alccofine replacement yielded splitting tensile strengths and flexural strengths which are respectively $7.07 \%$ and $1.63 \%$ higher than those of control mix at 28 days in normal curing conditions. But in marine curing conditions, concrete containing $15 \%$ fly ash and 5\% alccofine replacement yielded splitting tensile strengths and flexural strengths which are respectively $7.32 \%$ and $1.22 \%$ than that of control mix at 28 days.

$>$ The permit ion permeability test, which gives a measure of permeability and in turn durability indicated that concrete with less voids gave better durability. It was evident that the rate of conductivity decreases with the increase in fly ash content of cement in concrete. Concrete with 15\% Fly ash and alccofine 5\% decreased the permeability by $7.3 \%$ and $11.5 \%$ to that of control mix, in marine curing at 56 days and 150 days respectively.

$>$ Testing with Applied Corrosion Monitoring instrument, which uses a non-destructive test methodology, is a good alternative to measure the corrosion rate ( $\left.i_{\text {corr }}\right)$ in concrete. Concrete with higher fly ash content had lesser corrosion density than that of control mix

$>$ From results it is evident that concrete with 5\% alccofine and $15 \%$ fly ash, gave better mechanical and durability properties. On the basis of experimental results, fly ash based concrete with alccofine, subjected to marine environment are more durable.

\section{Acknowledgements}

The authors would like to thank Department of Civil Engineering, National Institute of Technology Karnataka, Surathkal for the support to do this experimental work. 


\section{References}

[1] Mackechnie, J. R. \& Alexander, M. G. (1997). "Exposure of concrete in different marine environments". Journal of materials in civil engineering, 9(1), 41-44.

[2] Dhir, R. K., El-Mohr, M. A. K. \& Dyer, T. D. (1997). "Developing chloride resisting concrete using PFA". Cement and Concrete Research, 27(11), 1633-1639.

[3] Wong, Y. L., Lam, L., Poon, C. S., \& Zhou, F. P. (1999). "Properties of fly ashmodified cement mortar-aggregate interfaces". Cement and Concrete Research, 29(12), 1905-1913.

[4] Hassan, K. E., J. G. Cabrera, \& R. S. Maliehe. (2000) "The effect of mineral admixtures on the properties of high-performance concrete." Cement and Concrete Composites, 22(4), 267-271.

[5] Shashiprakash, S. G., \& Thomas, M. D. A. (2001). "Sulfate resistance of mortars containing high-calcium fly ashes and combinations of highly reactive pozzolans and fly ash". Special Publication, 199, 221-238.

[6] Bader, M. A. (2003). "Performance of concrete in a coastal environment". Cement and concrete composites, 25(4), 539-548.

[7] Valipour, M., Pargar, F., Shekarchi, M., Khani, S., \& Moradian, M. (2013). "In situ study of chloride ingress in concretes containing natural zeolite, metakaolin and silica fume exposed to various exposure conditions in a harsh marine environment." Construction and Building Materials, 46, 63-70.

[8] Costa, A., and Appleton, J. (1999). "Chloride penetration into concrete in marine environment-Part I: Main parameters affecting chloride penetration". Materials and Structures, 32(4), 252-259.

[9] IS: 8112-1989, "43 Grade Ordinary Portland Cement - Specification”, Bureau of Indian standards (BIS), New Delhi, India.

[10]IS: 4031, "Methods of physical tests for hydraulic cement", Bureau of Indian standards (BIS), New Delhi, India.

[11]Alccofine official website - http://www.alccofine.com/knowledge-base (Aug27, 2015)

[12]IS: 2386-1963, "Methods of tests for aggregates for concrete", Bureau of Indian standards (BIS), New Delhi, India.

[13]IS 383-1970, "Specification for coarse and fine aggregates from natural sources for concrete", Bureau of Indian standards (BIS), New Delhi, India.

[14]IS: 456-2000, "Plain and reinforcement concrete - code of practice", Bureau of Indian standards (BIS), New Delhi, India.

[15]IS: 10262-2009, "Concrete mix proportioning - guidelines", Bureau of Indian Standards (BIS), New Delhi, India.

[16]IS: 516-1959, "Methods of test for strength of concrete", Bureau of Indian standards (BIS), New Delhi, India.

[17]IS: 9399-1979, "Specification for apparatus for flexural testing of concrete", Bureau of Indian standards (BIS), New Delhi, India.

[18]IS: 5816-1999, "Splitting tensile strength of concrete - Method of test", Bureau of Indian standards (BIS), New Delhi, India. 